\title{
A Review of Progressive and Compound Forming of Bulk Microparts by Using Sheet Metals
}

\author{
M.W. Fu ${ }^{1, *}, J . Y$. Zheng ${ }^{1}$, and B. Meng ${ }^{2}$ \\ ${ }^{1}$ Department of Mechanical Engineering, The Hong Kong Polytechnic University, Hung Hom, Kowloon, Hong Kong \\ ${ }^{2}$ School of Mechanical Engineering and Automation, Beihang University, Beijing 100191, P.R. China
}

\begin{abstract}
In the last decade, the concept of progressive microforming has emerged and developed gradually, which is considered as an efficient and promising method to fabricate the micro-scaled part. Micro-cylinder parts, micro-flanged part, and multi-flanged microparts are representative micro bulk parts by the progressive microforming system using sheet metal. In these cases, many efforts focus on the forming process, such as microblanking and microextrusion. Meanwhile, the quality of the fabricated parts also attracts attention. In this paper, an intensive review on the development of progressive microforming technologies and the formed parts is presented, and the influence of size effect to dimensional accuracy, material flow, geometrical feature, and fracture is also discussed.
\end{abstract}

Keywords: Micro forming, Deformation, Sheet metal

\section{Introduction}

Due to the increasing demand of product miniaturization in microelectronics, biomedicine, consumer electronics and other industrial clusters [1-4], microforming technologies are gaining more attention and development effort. Microforming is defined as the production of micro-scale parts or structures with at least two dimensions in the sub-millimeter range [2]. This process is considered as a promising micro-manufacturing method due to its good productivity, high material usage, nearnet-shape characteristic and the good mechanical properties of the deformed parts [1].

The experience of manufacturing macro-scaled parts cannot be applied directly in the fabrication of microparts due to size effect [3-6]. Fu and Chan [7] reviewed the state-of-the-art microforming technologies and had a panorama of the research in the last two decades on size effect related deformation behaviors, and discussed some research issues from the implementation of mass production. However, some critical issues such as dimensional accuracy of parts, final part damage control and positioning in production processes cripple the application of microforming in mass production.

To solve these problems and meet the increasing demands, the concept of progressive and compound microforming emerged and developed gradually. Fig. 1 shows some progressive microformed parts. Progressive microforming is one of the state-of-the-art microforming processes [8], which is a forming technology to fabricate micro-scale parts by using progressive forming process. In each progressive forming operation, one or more distinct die is used and after the specific processing sequence, a complete part is fabricated from metal strips.

Regarding this process, Hirota [9] firstly proposed a new method to fabricate micro-pin parts by extruding a metal sheet in the thickness direction. Ghassemali et al. $[10,11]$ adopted this process to produce axisymmetric parts with micro-pins and investigated the phenomena of variations of material flow and microstructure evolution due to the size effect. According to this novel method, further researches have been conducted. Fu and Chan [12, 13] investigated the feasibility of fabricating the bulk cylinders and flanged parts via directly using sheet metal in meso- and micro-scales, and the characteristics of final parts, as well as the production process, were examined. They also discussed the relationship between grain size and deformation behaviors. Based on the prior studies, Meng et al. [14-16] conducted further and extensive studies of micro progressive forming. In these cases, the cylinder, double-flanged and variable-thickness flanged microparts were manufactured by progressive microforming, respectively. They further investigated the micromechanical damage and deformation behavior in progressive microforming and developed the systematic knowledge for micro-formed part design.

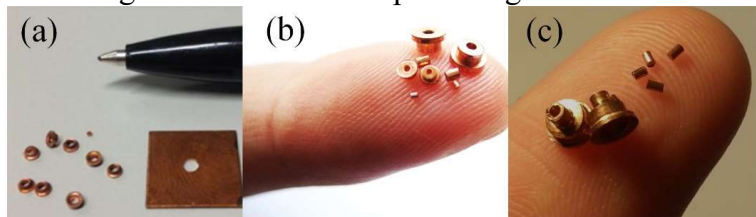

Fig. 1 (a) micro flanging-ironed parts [16], (b) micro-flanged parts [13], (c) micro multi-flanged parts [14].

\footnotetext{
*Corresponding author: mmmwfu@polyu.edu.hk
} 
Base on the shapes of bulk parts, three types of progressive microforming parts can be classified according to the previous research: micro-cylinder parts, micro-flanged/ironed parts and multi-flanged microparts.

Although the researches on progressive microforming processes have been conducted for many years and several modeling methodologies have been established, there are still some problems that impede the application of the progressive microforming, and it still contains many unknowns behind size effects. In this paper, the studies on the processes of progressive microforming and fabricated microparts are reviewed comprehensively. To provide a summary of the progressive microforming technologies and progressive tooling and parts design. The mechanism of how the size effect affects the deformation behavior and characteristics of microparts is discussed, including the evolution of microstructure, fracture behavior, dimensional accuracy, and undesirable geometry, etc.

\section{Progressive formed parts}

\subsection{Micro-cylinder parts}

Cylinder parts can be fabricated via cutting metal wire or blanking metal sheets, and the latter is proved as a more considerable method. In this process, both microblanking and micropunching are shearing operations with the advantage of low cost and high productivity over the micromachining processes. Microblanking is employed to produce bulk metal parts from sheet metals, while micropunching is a simple process for fabrication of microholes [8].

Among the prior arts, $\mathrm{Xu}$ et al. [17] conducted microblanking experiments via using brass foil to investigate the size effect on deformation behavior. Fu and Chan [12, 13] conducted experiments by designing two scales of progressive forming systems to fabricate meso-/microcylinder parts via microblanking process and focused on the characteristic of formed parts. Meng et al. [14-16] extensively investigated the material deformation behavior and the fracture effect of shearing in microcylinder parts forming processes by using the same method. In addition, the influence of forming conditions on deformation behavior, fractured surface quality and dimensional accuracy in shearing operation were systematically investigated.

\subsubsection{Evolution of microstructure}

Meng et al. [15] conducted research on the blanked part. The microstructure of the micro-cylinder part can be divided into four zones (I-IV) according to the variation of grain sizes and stress states, and the stress states during the shearing process are also presented via FE simulation, as shown in Fig. 2. Among these zones, the less-deformed zone, Zone I is defined as the dead zone by Ghassemali et al. [18]. The highly elongated and rotated grains close to the shear bands can be seen in zone IV. When the elongated grains extend to the center section, zone II is compressed to be formed. The arched shape is associated with the different flow velocities between the center and sides. Zone III is the gradient distribution zone. The material in zone II is subjected to the tensile stress in the horizontal direction, which is induced by the restriction near the edge of moving punch. The tensile stress in zone II transmits the punching force to the punch edge to separate the material from the sheet metal. Furthermore, the bandwidth of zone II is related to the original grain size. As the fine-grained material is used, the grains are distributed evenly in zones II and III, thus the compressive band is not obvious. The stress state of zone I is under triaxial compressive stress, which is attributed to the fact that zone II hinders the material in zone I to flow to both sides. The grain size of zone III increases to the rollover gradually. The stress state of zone III is the same as that in zone II, but the tensile stress is lower, resulting in the gradient distribution of grain size.

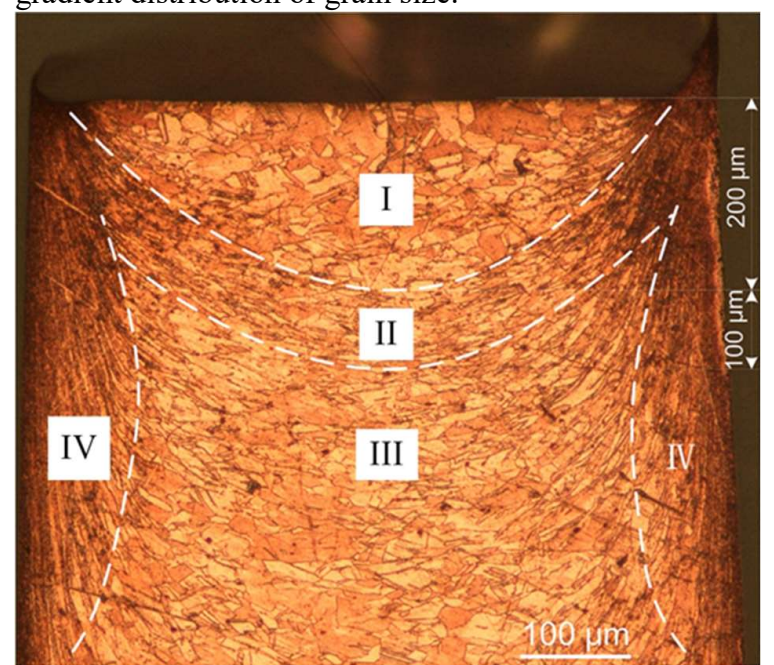

Fig. 2 Evolution of microstructure of the blanked part (zone I, II, III, IV) [15].

\subsubsection{Deformation load}

Deformation load represents the energy needed during the forming process, which should be as small as possible, so it could be used as one of the criteria in part design. Fu and Chan [12] indicated there were three stages of the shearing process in blanking operation which is shown in Fig. 3. In the first stage, punch presses the workpiece to deform elastically and then plastically, resulting in strain hardening and the increase of deformation load. In the second stage, the material is further pushed forward into the die by shearing. The length of the shear band decreases with the punch penetration, causing the decrease of deformation load. In the third stage, the deformation exceeds its limit and fracture took place. This leads to a sudden decrease of deformation load. The remaining load after fracture is to overcome the frictional force at the tooling-workpiece interface.

Meng et al. [15] investigated the interactive effect of grain size, the lubricated condition and the velocities on the micro shearing process. It is revealed the scatter of shearing load increases with grain size using mechanical oil or grease lubricant. The deformation load is reduced by using grease lubricant, but its scatter increases. The 
lubricant with low viscosity has a limited role in the shearing process, and the high viscosity lubricant is more effective.

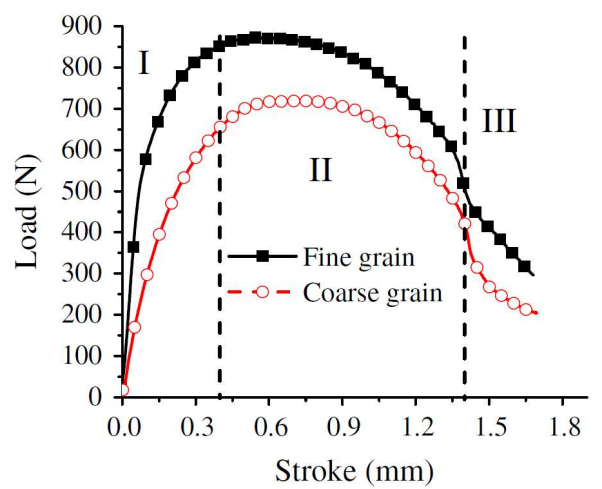

Fig. 3 Load-stroke curves in the blanking operations for the materials with different grain sizes [12].

\subsubsection{Ultimate shear stress}

The ultimate shear strength is obtained based on the following equation [19]:

$$
\sigma_{s}=\frac{F_{\max }}{\pi d l}
$$

where $F_{\max }, d$ and $l$ are the maximum shearing force, punch diameter and the thickness of sheet material, respectively. Xu et al. [17] indicated the ultimate shearing strength increases with the decrease of the foil thickness. $\mathrm{Fu}$ and Chan [13] got the same conclusion by using two scales of forming systems. In the researches of $\mathrm{Xu}$ et al. [17] and Meng et al. [15], the ratio of blanking clearance to grain size c/g (Fig. 4) becomes one of the main factors to influence the deformation behavior of micro punching/blanking, and there exists a minimum peak value when $\mathrm{c} / \mathrm{g} \approx 1$, as shown in Fig. 5. When $\mathrm{c} / \mathrm{g}>1$, the punch-die clearance has the width of several grains, and the shear band involves a large number of grain boundaries. When $\mathrm{c} / \mathrm{g}<1$, the deformation of grain matrix takes leading position in the shearing band, and the grain boundary sliding is still dominant in the thickness direction. When $\mathrm{c} / \mathrm{g} \approx 1$, the clearance can only accommodate one grain. In this condition, the grain boundary sliding and coordination in the clearance width direction reduces to a minimum level, meanwhile the grain matrix deformation reaches the lowest magnitude. So the ratio of punch-die clearance to grain size leads to the lowest shearing stress when $\mathrm{c} / \mathrm{g} \approx 1$.
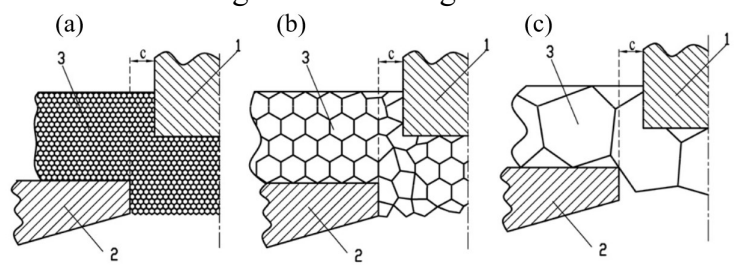

Fig. 4 Size effect model of grain size in micro-punching 1-micro punch; 2-micro die; 3-metal foil:(a) $\mathrm{c}>\mathrm{g}$; (b) $\mathrm{c} \approx \mathrm{g}$ and (c) $\mathrm{c}<\mathrm{g}$ [17].

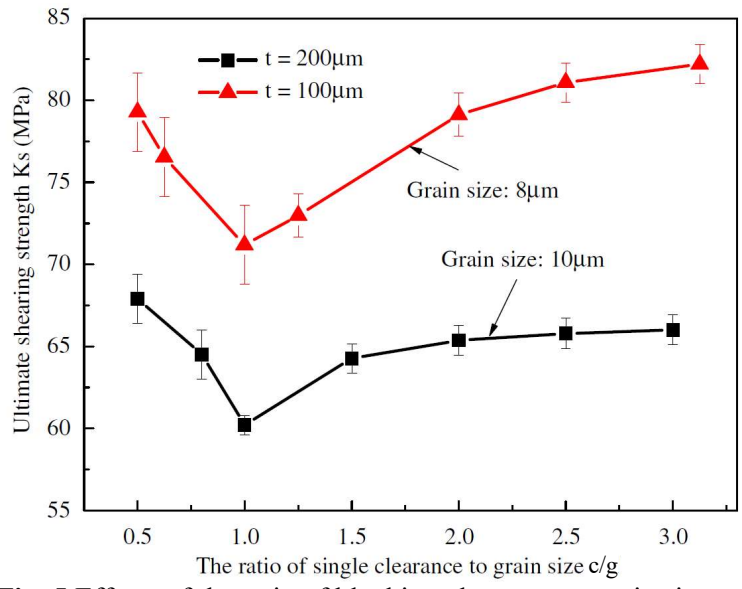

Fig. 5 Effects of the ratio of blanking clearance to grain size on ultimate shearing strength [17].

\subsubsection{Dimensions accuracy of microparts}

$\mathrm{Fu}$ and Chan [13] revealed that the length of blanked cylinder decreases with the increase of grain size, which is attributed to the aggravated lateral material flow when using the coarse-grained material, as shown in Fig. 7. When the grain size is large compared to the blanked cylinder, the individual grain properties become significant and make the deformation inhomogeneous, which further results in the irregular shape of the blanked cylinder. In the subsequent researches, Meng et al. [14-16] fabricated different micro-cylinder parts, as shown in Fig. 7, and the results supported the prior conclusion. It is found that the length of the blanked cylinder decrease but the diameter increase by grease lubricant, and the billet diameter reached the maximum when the punch-die clearance is close to grain size, as shown in Fig. 8.

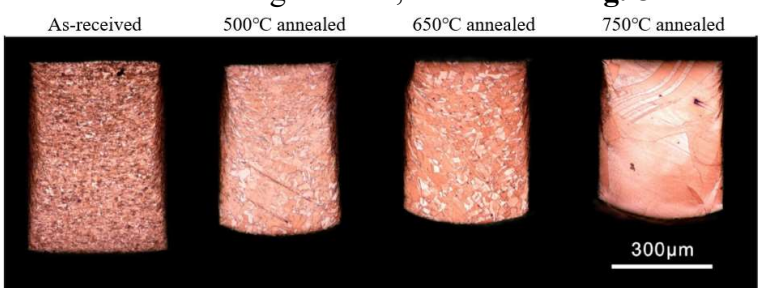

Fig. 6 Microstructures of the blanked cylinders with different material states of the micro-scaled case [13].

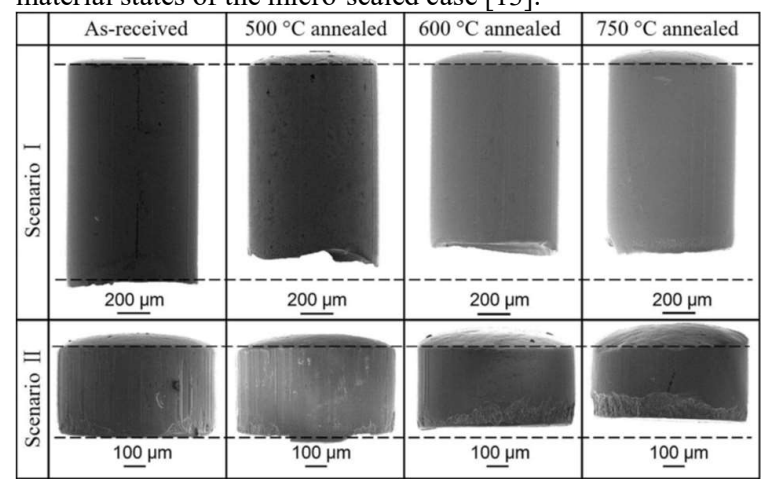

Fig. 7 Comparison of the length and final shape of the fabricated micro-pins [16]. 


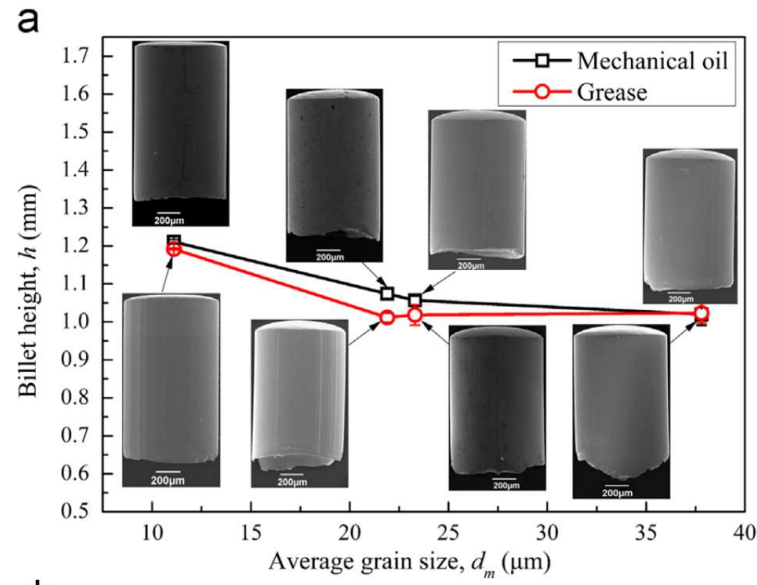

b

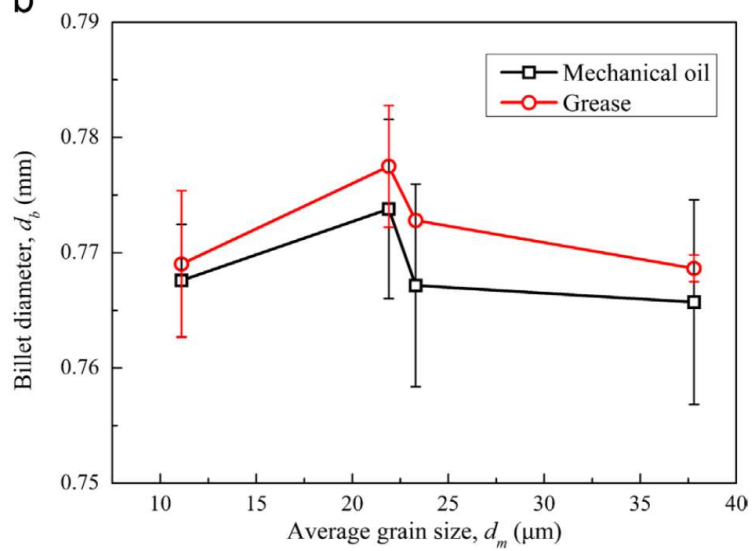

Fig. 8 Dimensions of the blanked part: (a) height and (b) diameter [15].

\subsubsection{Fracture}

The fracture mechanism based on the initiation, growth, and coalescence of microvoids, which can only occur at the grain boundaries or inclusions, results in the rough surface finish. The irregular shape of the blanked microbillet and the inclined fracture surface could be found as shown in Fig. 9.

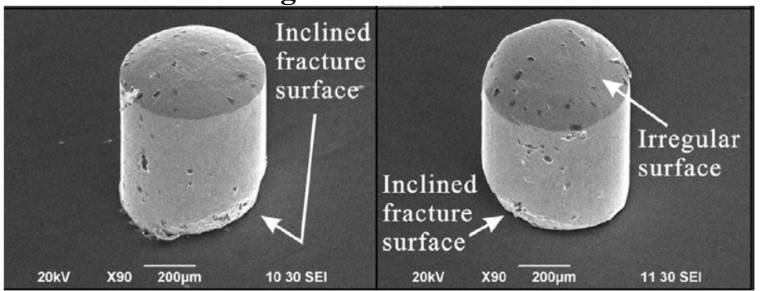

Fig. 9 The irregular blanked billets in micro-scaled case [13].

$\mathrm{Xu}$ et al. [17] indicated that the fracture mechanism of micro-blanking significantly changes from fracture mode with ductile dimples as shown in Fig. 10 (a) and (b) to ductile fracture with slip separation as shown in Fig. 10 (c) with the decrease of foil thickness. Meanwhile, the number of the dimple is decreased with the brass foil thickness. The irregularities occur which can strongly affect the fracture with the decrease of blanking clearance, as shown in Fig. 11. However, the fracture mechanism does not significantly change with ductile dimples with the decrease of blanking clearance, which indicates that blanking clearance has no effect on fracture of microblanking. In addition, grain size has no effect on fracture mechanism of micro-blanking, as shown in Fig. 12.

Meng et al. [15] found that there are no obvious dimples on the blanked surface of the micro-cylinder part, especially for the coarse-grained material. In addition, the high velocity worsens the surface finish. The surface breakages on the blanked part appear under the high shear velocity due to the inhomogeneous deformation rate throughout the shear band, as shown in Fig. 13.
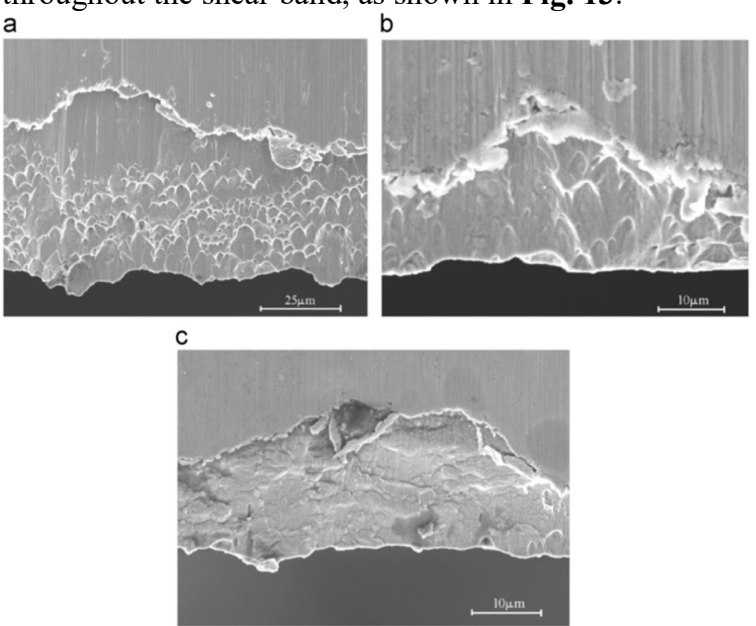

Fig. 10 Effect of foil thickness on fracture morphology of crosssection. (a) $\mathrm{t}=200 \mu \mathrm{m}$; (b) $\mathrm{t}=100 \mu \mathrm{m}$ and(c) $\mathrm{t}=60 \mu \mathrm{m}$ [17].
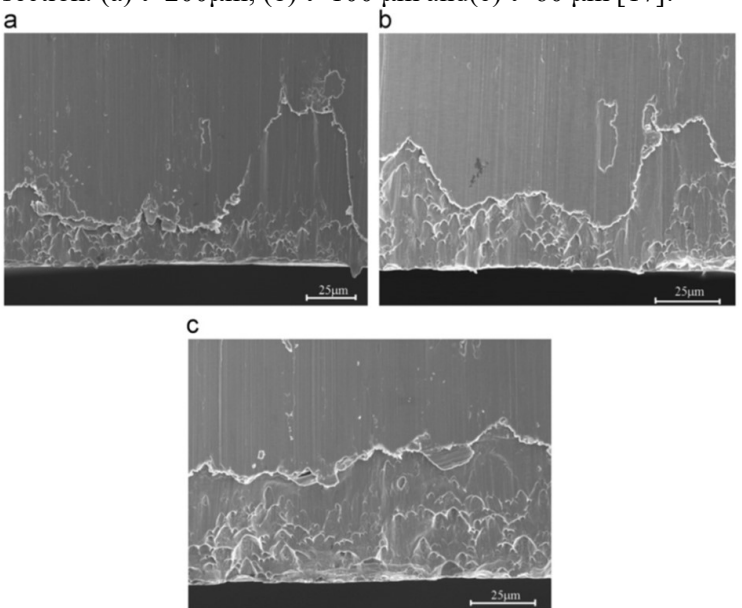

Fig. 11 Effect of the blanking clearance on fracture morphology. (a) $\mathrm{c} / \mathrm{t}=2.5 \%$; (b) $\mathrm{c} / \mathrm{t}=5 \%$ and(c) $\mathrm{c} / \mathrm{t}=10 \%$ [17].

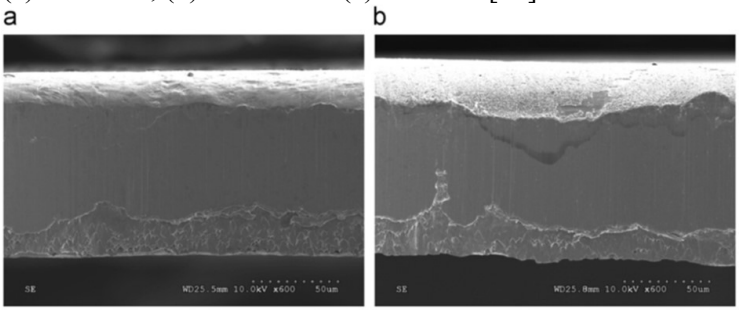

Fig. 12 Effects of grain size of foil on the cross-section in micro blanking. (a) $d=8.2 \mathrm{~mm}$ and (b) $\mathrm{d}=98.2 \mathrm{~mm}$ [17]. 


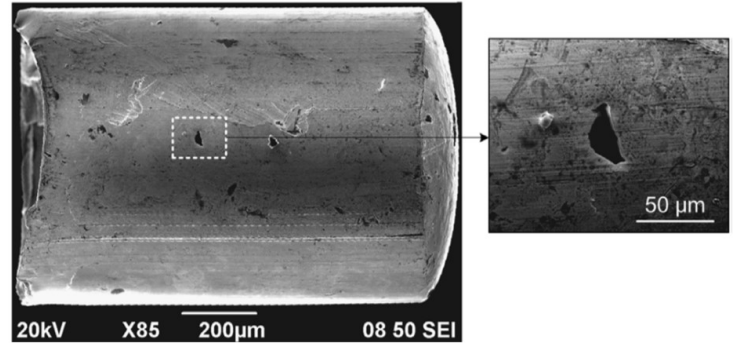

Fig. 13 Surface breakage on the sheared part [15].

\subsubsection{Rollover of sheet}

Fu and Chan [12] revealed the rollover size is large and the rollover surface becomes rough with the increase of grain size, which could be related to the large hardening exponent and attributed to the fact that strain incompatibility among grains makes the surface grains move normal to the surface to accomplish deformation, as shown in Fig. 14.

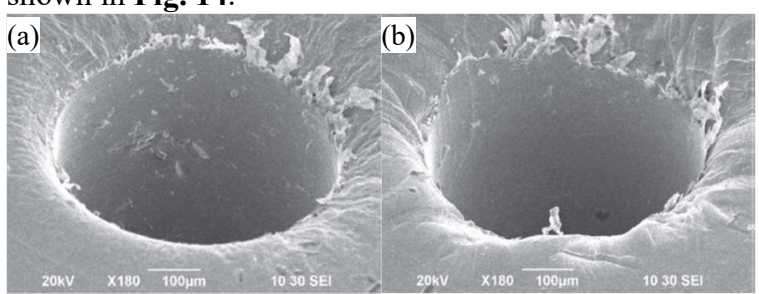

Fig. 14 The pierced holes with different material states in the micro-scaled case (a) $500^{\circ} \mathrm{C}$ annealed (b) $750^{\circ} \mathrm{C}$ annealed [12].

\subsubsection{Undesirable geometries}

Meng et al. $[15,16]$ conducted further and extensive study of the micro-cylinder part forming under interactive effects of multi-factors, including grain size, lubricated condition, shear velocity and die dimensions. In this research, the micro-cylinder part was divided into different zones, as shown in Fig. 15. The experiment results with different grain sizes, dimensions of the part, lubricated conditions and shear velocities are shown in Fig. 16 to Fig. 18. It is revealed that the forming quality deteriorates with the increase of grain size and shear velocity. In addition, a high ratio of thickness to diameter of the micro-cylinder part and high viscosity lubricant leads to the good surface finish.

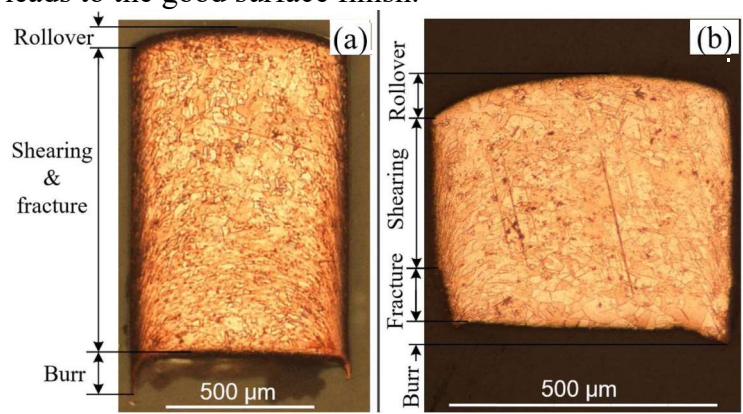

Fig. 15 Different zones of the sheared micro-part: (a) $d=0.74 \mathrm{~mm}$, $\mathrm{l}=1.52 \mathrm{~mm}$; (b) $\mathrm{d}=0.6 \mathrm{~mm}, \mathrm{l}=0.4 \mathrm{~mm} \mathrm{[16].}$

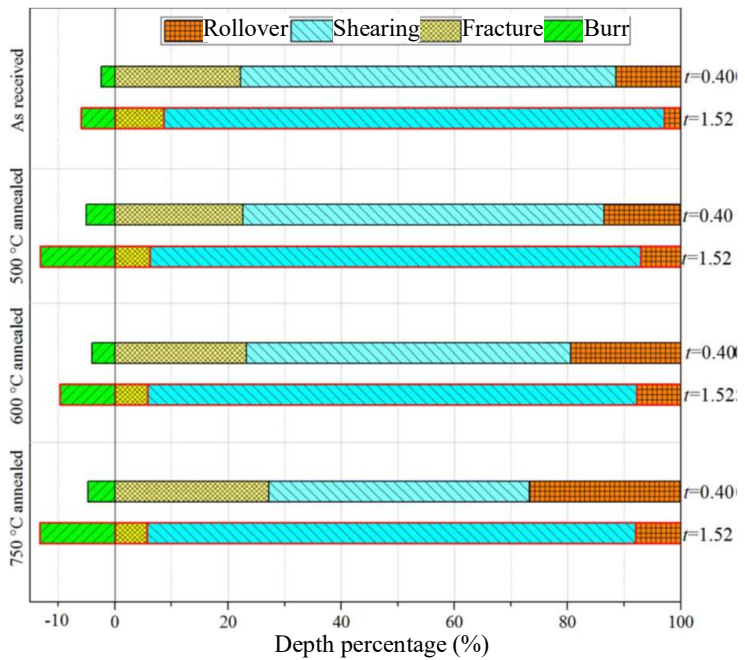

Fig. 16 Distributions of different zones of the blanked part under diverse material conditions [16].
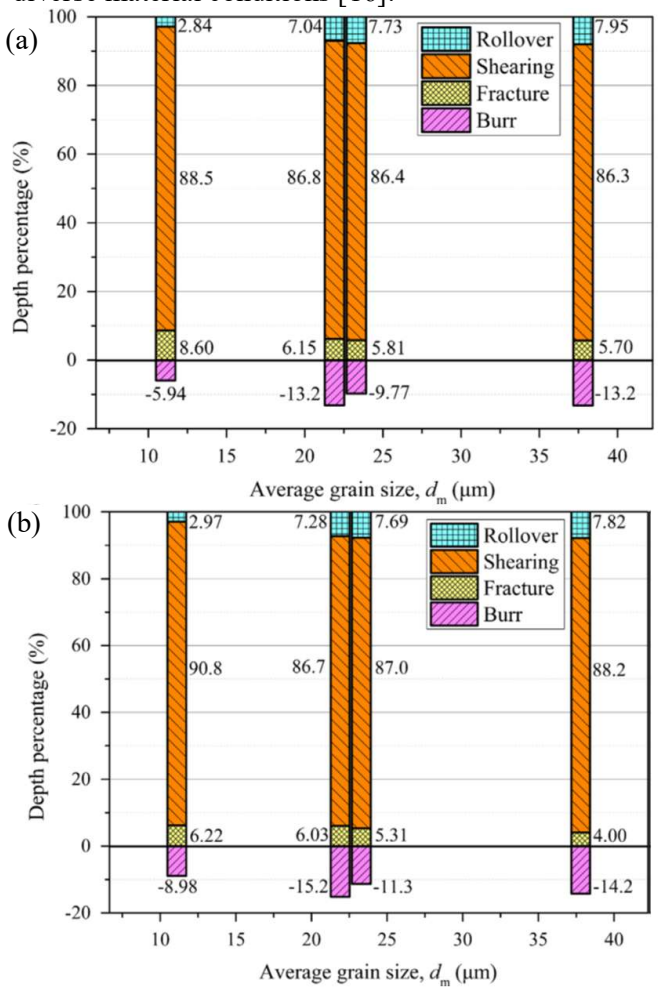

Fig. 17 Dimensions of different zones of the blanked part under different lubricated conditions: (a) mechanical oil (b) grease [15].

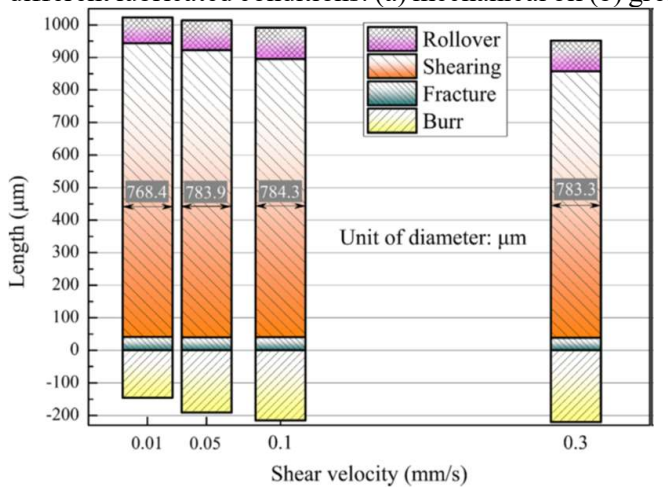

Fig. 18 Dimensions of the blanked part using various shear velocities [15]. 


\subsection{Micro-flanged/ironed parts}

Micro-flanged/ironed parts are fabricated by extrusion and blanking processes base on guide hole after punching process. Forward extrusion is defined as a plastic deformation process in which billet material is compressed in the die and the material flows in the same direction as the movement of punch [8]. Microextrusion is widely investigated in terms of size effect, constraint condition, and tooling-workpiece interfacial friction.

$\mathrm{Fu}$ and Chan $[12,13]$ used the progressive forming system to fabricate the flanged parts via the progressive punching, extrusion, and blanking. In the second operation, the workpiece was positioned based on the guide hole, and the material was pushed to flow towards die cavity. Then the flanged part was blanked from the sheet. Pure copper sheets with the thicknesses of $1.5 \mathrm{~mm}$ as meso-scale and $0.8 \mathrm{~mm}$ as micro-scale are selected as testing material. Various grain sizes were obtained via heat treatment. The forming process and the flanged part are shown in Fig. 19.

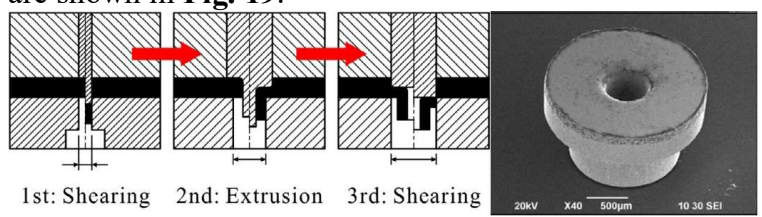

Fig. 19 The flanged parts and the progressive forming system [13].

Meng et al. [16] developed a promising and efficient progressive microforming method to fabricate microscaled hollow geometries with higher flange and variable thickness by using an integrated hole flanging-ironing process, as shown in Fig. 20. The pure copper sheet metal with the thickness of $0.4 \mathrm{~mm}$ was chosen as the experimental material, and the sheets were annealed to obtain different grain sizes. The progressive micro forming system consists of three forming steps, viz. shearing, hole flanging-ironing, and blanking. A microhole was punched and a micro-pin part was blanked out after the first operation. And then the fine pre-pierced hole is used for positioning and a long flange is formed by micro-scaled hole flanging-ironing process. The last operation was used to blank out the micropart from the workpiece.

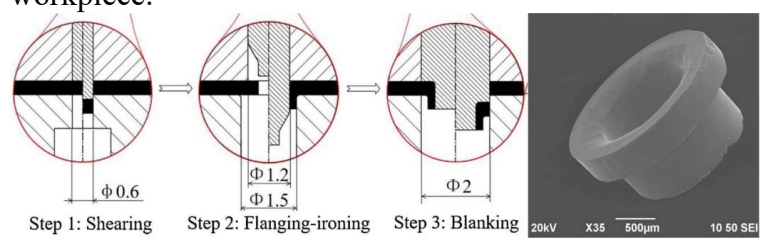

Fig. 20 The ironed micropart and its forming process [16].

\subsubsection{Evolution of microstructure}

Fu and Chan [13] investigated shear bands connecting the punch and die edges forming after the second operation in progressive microforming, as shown in Fig. 21. The flowing material is constrained by the surrounding material outside the deformation zone. The shear band divides the material flow into two directions. The inner material flows towards the die cavity to contribute the length of the extrudate, while the outer material flows laterally. In the second stage, the material in between the punch and die edges are subject to shearing deformation. The length of shear band decreases with the increase of punch stroke.

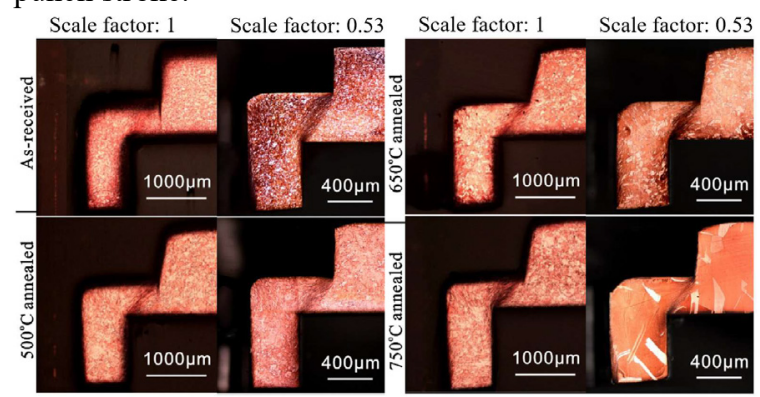

Fig. 21 Microstructures in the second forming operation [13]

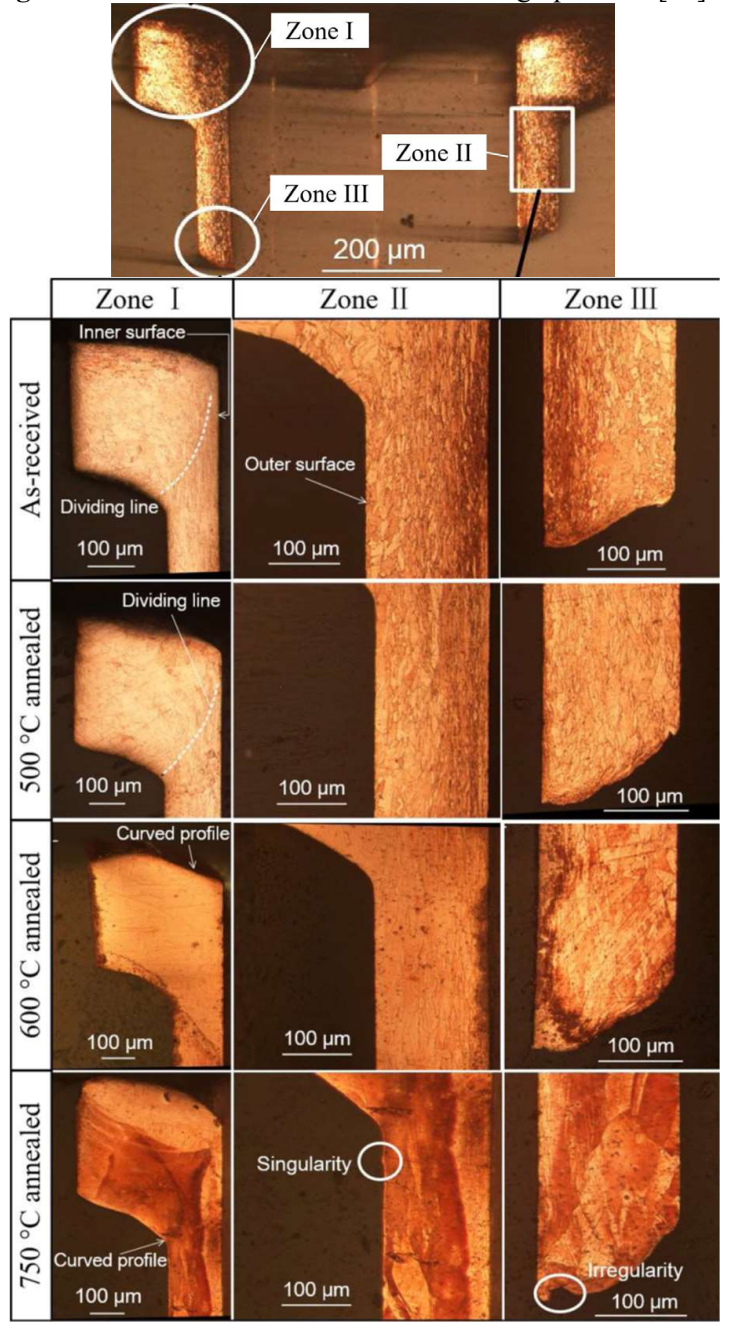

Fig. 22 Microstructural evolution in the integrated micro-scale hole flanging-ironing process [16].

In the study of Meng et al. [16], the evolution of microstructure was observed, as shown in Fig. 22. It is discovered that the hole flanging-ironing process produces a flanged feature with a curved profile followed by a straight wall, and the short curved profile and the desirable boring straightness are achieved by using the fine-grained material. zone I is the junction between the blanked part and the flanged edge, and the demarcation 
lines were observed to distinguish the bending region and the zone of edge stretching and ironing deformation with fine-grained materials. The inhomogeneous microstructure distributions are induced by the formation of dead zone [18]. However, the separatrix becomes blurred for coarse-grained materials. This phenomenon is caused by the decrease of the grain number involved in the deformation zone when the grain size is equivalent to the geometrical dimension of the workpiece. Singularities were observed in zone II at the outer profile of the flanged edge using the coarse-grained material. This could be attributed to the loss of the grain number and enhanced anisotropic properties of individual grains. It is found from zone III that the generated irregularities at the flanged tip are intensified with the increasing grain size.

\subsubsection{Deformation pressure}

A typical load-stroke curve of the microextrusion process is shown in Fig. 23, in which the difference between two curves was influenced by rollover caused by the last operation. It can be seen that the deformation load decrease with the increase of grain size.

The variation of the deformation load in the microscaled hole flanging-ironing process and the corresponding deformed shapes are presented in Fig. 24. Five deformation stages including elastic deformation, deflexion, flow forming, ironing, and sliding are identified in the micro-scaled hole flanging-ironing process, and the deformation load increases with the decrease of grain size.

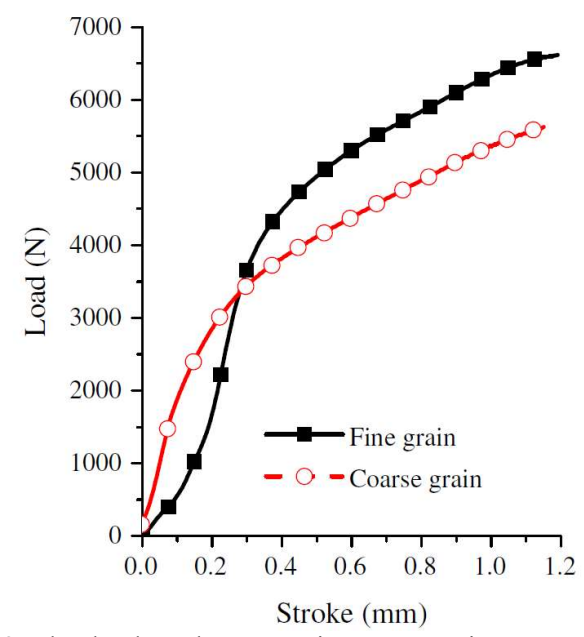

Fig. 23 The load-stroke curve in an extrusion process with different grain sizes [12]

\subsubsection{Dimension accuracy}

Meng et al. [16] examined the dimensional accuracy of height and tapering angle between inner and outer surfaces of the flanged micropart as shown in Fig. 25. It is revealed that the length of the flanged micropart is reduced with the increasing grain size, while both the tapering angle and its scatter present an opposite tendency, which could be explained by the coupled model of free surface roughening and open-closed lubricant pockets.

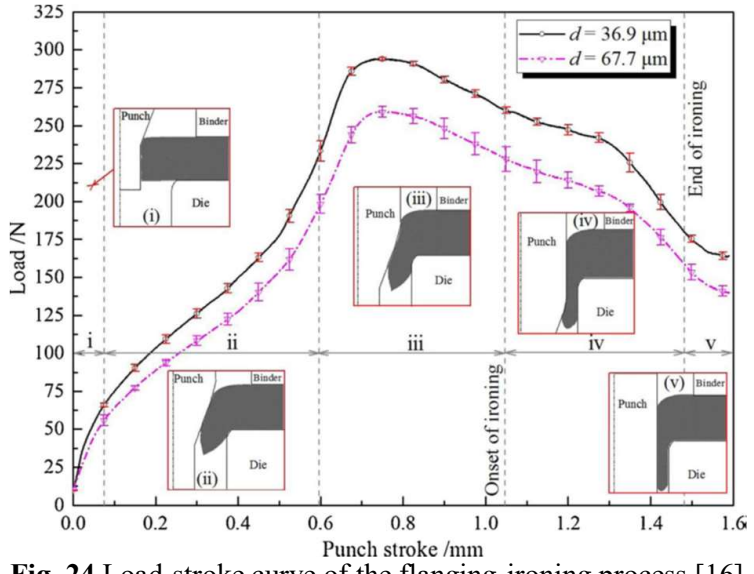

Fig. 24 Load-stroke curve of the flanging-ironing process [16]
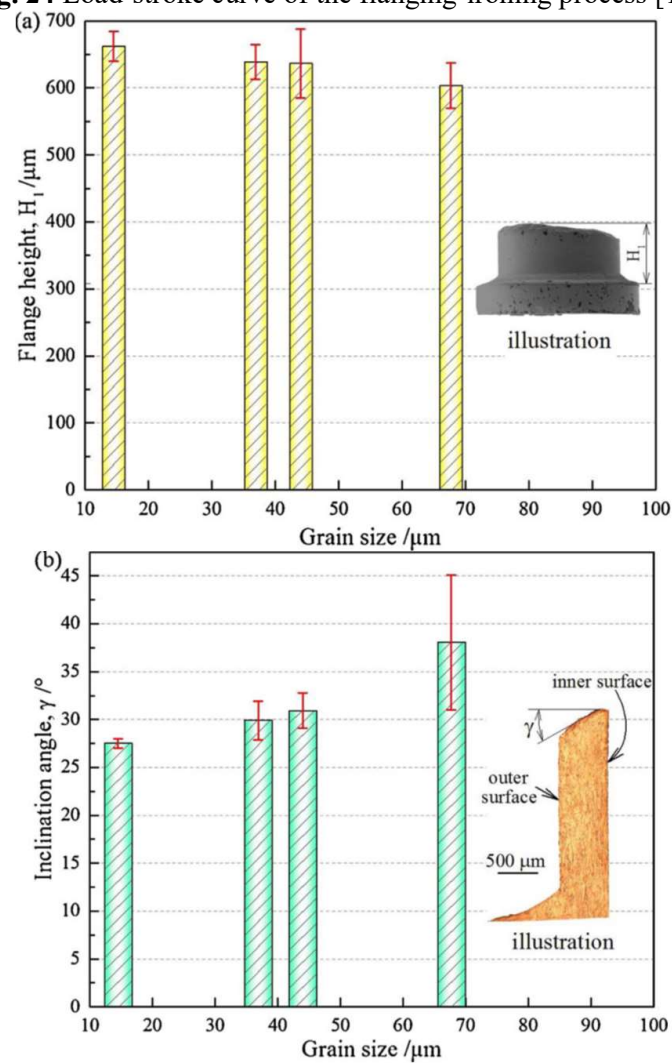

Fig. 25 Effect of grain size on the geometric dimensions of the flanged part: (a) flange height, and (b) tapering angle between inner and outer surfaces [16].

\subsubsection{Fracture}

Shearing and fracture regions could be found on the blanked surface of the micro-scaled part, as shown in Fig. 26. It can be seen that the parabolically shaped microvoids occurred on the fracture surfaces and the number of microvoids decreases with the increase of grain size. But the size of fracture surface does not have a significant change in the decreasing number of grains over the thickness of the workpiece.

Fracture and shearing surface were observed on the blanked part after the third operation. In the flanged ironing micropart, it is found that the flanged microparts with the fine-grained materials have the desirable forming 
quality. The surface integrity of the formed part worsens with the increasing grain size, and the irregularity occurred. Meanwhile, the surface integrity of the junction between the flanged edge and the non-deformed zone also changes with the grain size. The surface of the coarsegrained material becomes rough.

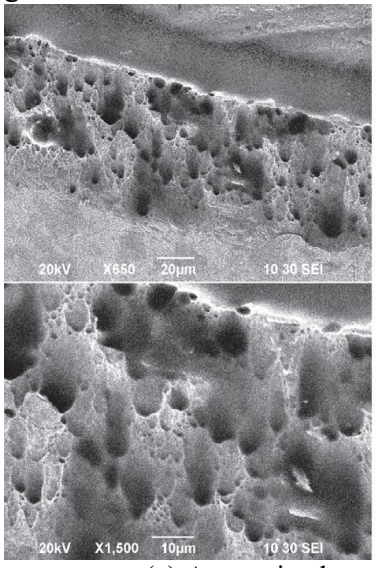

(a) As-received

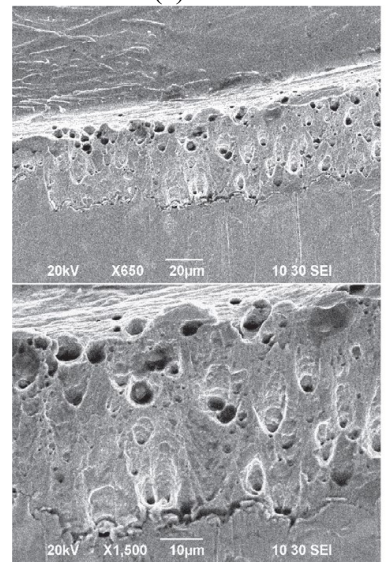

(c) $650^{\circ} \mathrm{C}$ annealed

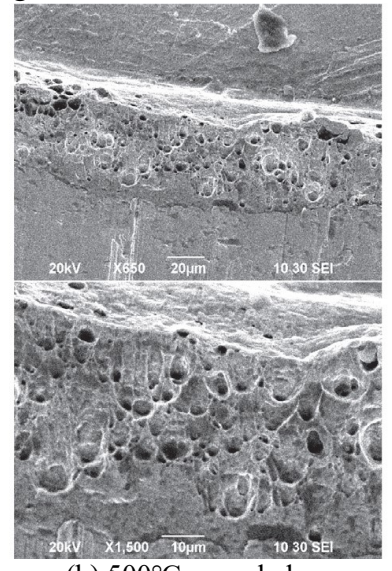

(b) $500^{\circ} \mathrm{C}$ annealed

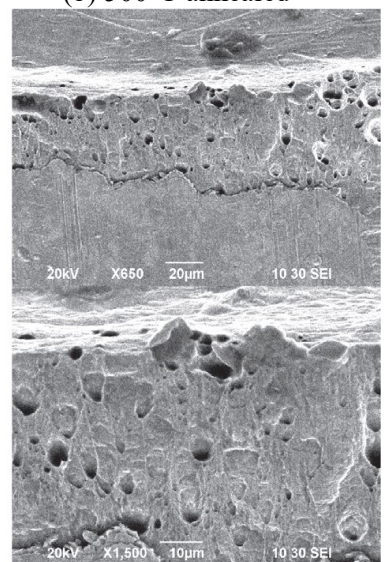

(d) $750^{\circ} \mathrm{C}$ annealed
Fig. 26 The fracture surfaces of the micro-scaled parts with different material states [13].

\subsection{Multi-flanged parts}

The multi-flanged part was fabricated by progressive microforming with micropunching, two microextrusions, and microblanking in the study of Meng et al. [14], as illustrated in Fig. 27. This study aimed at the effect of grain size on material flow, geometrical features, dimensional accuracy and fracture behavior in microforming. The validity of different fracture criteria in microforming was also discussed.

\subsubsection{Evolution of microstructure}

The shear bands extending from punch edge to die orifice occurred in two continuous extrusion operation, as shown in Fig. 28. The grains in the shear bands undergo plastic deformation, and the effective strain is highly localized in this region. The width of the shear bands decreases with the increase of grain size. The shear band involves a large number of grains to participate in the plastic deformation using the fine-grained material, resulting in more severe deformation in this region.
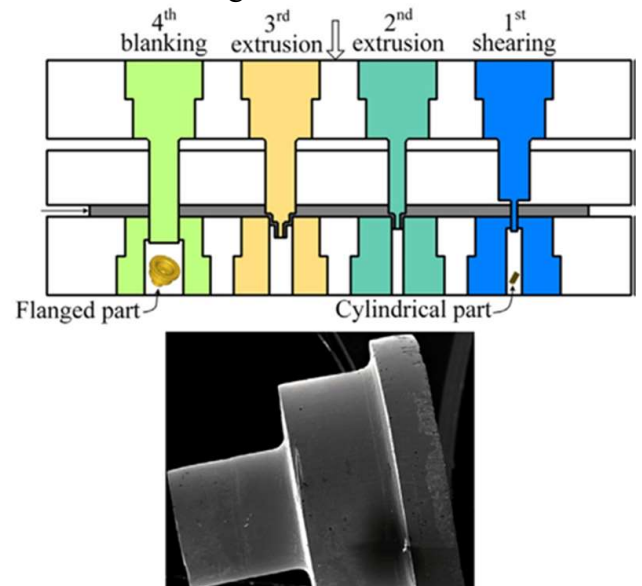

Fig. 27 Schematic illustration the progressive forming system of a multi-flanged part [14].

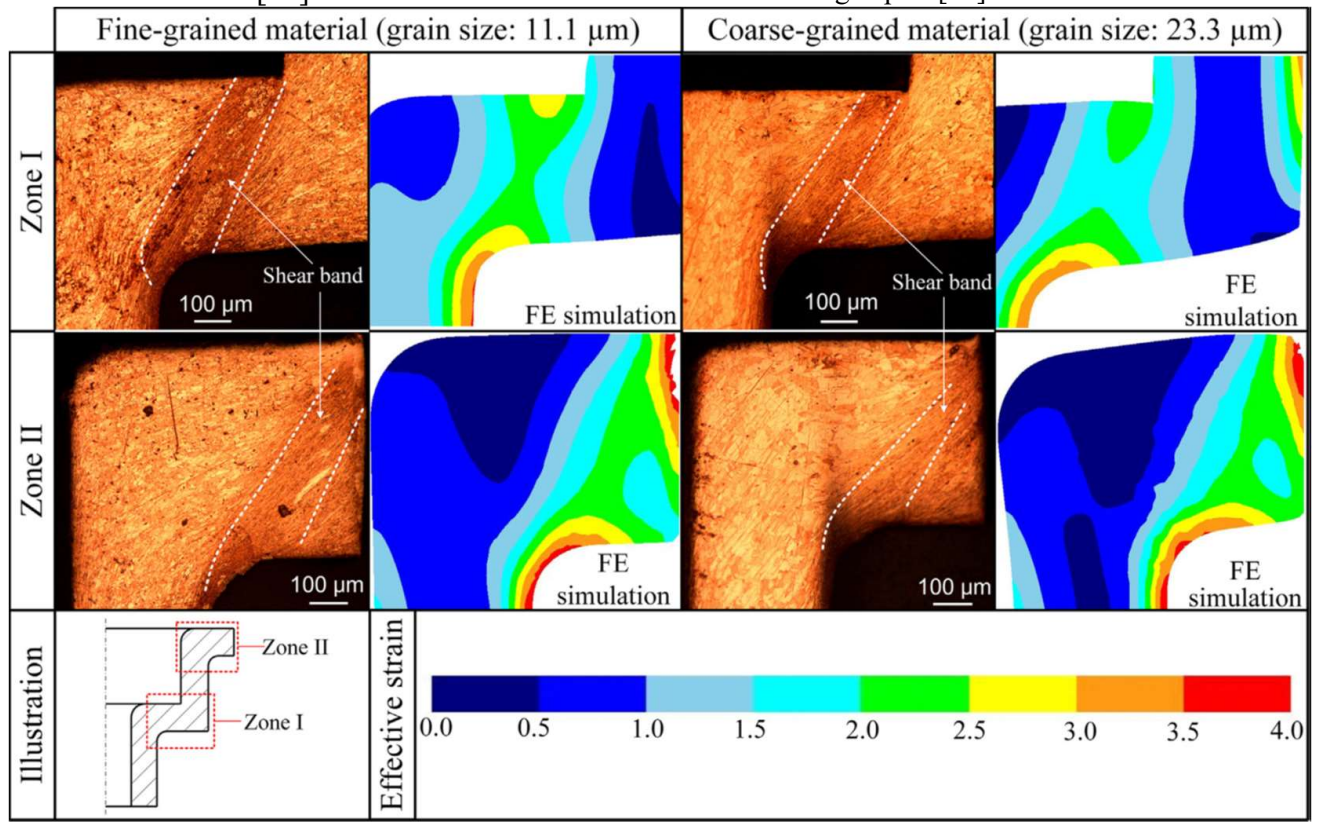

Fig. 28 Shear bands and effective strain calculated by FEM in the extrusion processes [14]. 


\subsubsection{Geometrical features}

The irregular geometric defects of the multi-flanged part are identified to exist in the three regions, as illustrated in Fig. 29. It is observed that the undesirable deformation deteriorates with the increase of grain size. The serious inclination of the flanged feature, irregular shape as well as the obvious burr is found using the coarse-grained material. This is due to the fact that the size and orientation of individual grains affect material flow behavior significantly when the characteristic dimension is in the order of grain size. In addition, the material stiffness and strength are reduced for the material annealed at high temperature, which contributes to the further deformation of the formed features.

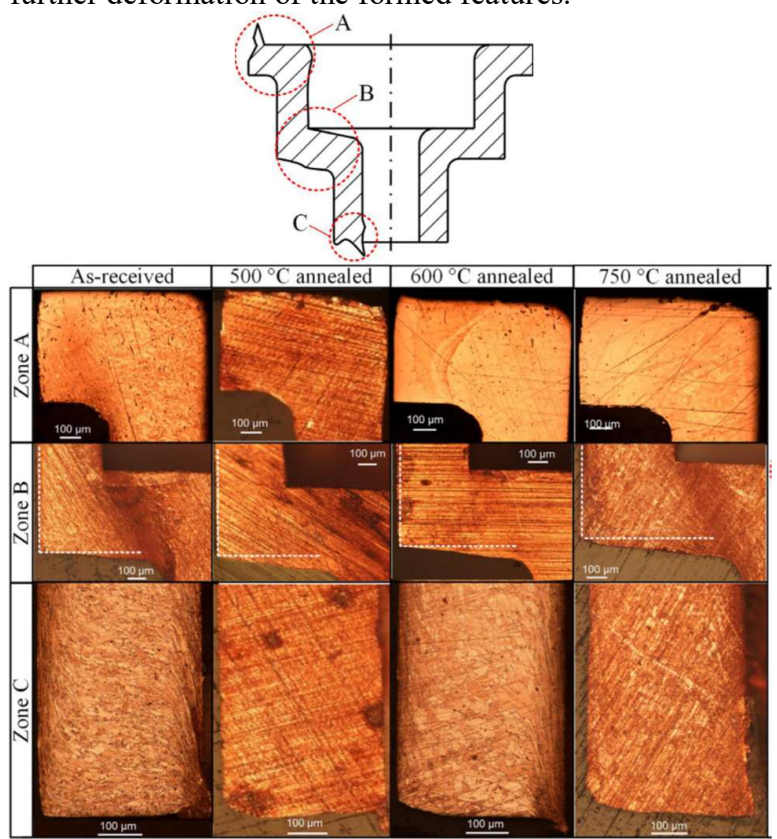

Fig. 29 Geometrical features of the flanged part after progressive deformation [14]

\subsubsection{Dimensional accuracy}

The dimensional variation of the two-level flanged parts is shown in Fig. 30. It is found that the diameters of the flanged part have the same geometries for both the fineand coarse-grained materials, in contrast to the length of the extrudate shows a decreased tendency with the increase of grain size. This is caused by the fact that the deformation along the diametrical direction was restricted by tooling, while the material along the length direction underwent free deformation.
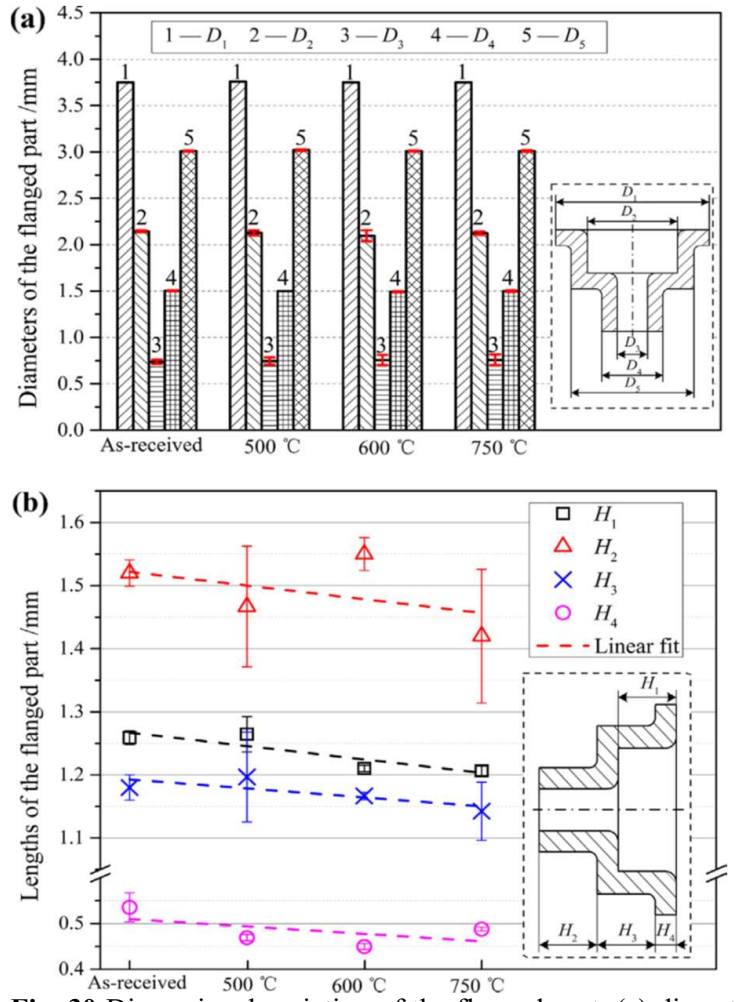

Fig. 30 Dimensional variation of the flanged part: (a) diameter and (b) length [14]

\section{Conclusion}

Progressive forming is proven to be a feasible and efficient microforming technology for production of micro-scaled parts. However, the occurrence of size effect while miniaturization of the forming system and parts results in some issues. In this paper, the state-of-the-art researches and the latest development of progressive microforming systems are reviewed comprehensively.

Dead zones of the deformed parts the shear band can be observed on the cross-section, which reveals that the material flow toward inner and outer from the shear band in the progressive microforming process, and less deformed area occurs far from the shearing area. Hardness test on the cross section shows that the largely deformed area has high hardness compared to the dead zones, and the hardness distribution supports the conclusion.

The deformation load in progressive microforming decreases with the increase of grain size, both in microblanking and microextrusion. This has a good agreement with the Hall-Petch relation. In addition, high viscosity lubricant can reduce the deformation load.

There is a minimum ultimate shear stress in the microblanking process when the grain size is equal to punch-die clearance, since the grain boundary sliding and coordination, as well as the grain matrix deformation, reach the lowest magnitude. The ultimate shear stress also increases with the decrease of the thickness of the metal sheet, because with the decrease of grains involved in shear deformation, slip and coordination of grains are difficult, leading to large shearing resistance. 
The height of micro-cylinder parts, microflanged/ironed parts and multi-flanged part decreases with the increase of the grain size, but tapering angle of flanging-ironed parts has an opposite tendency. The height of micro-cylinder parts decreases and the diameter of them increases with the high viscosity lubricant. There is a maximum diameter when the grain size is equal to punch-die clearance.

The forming quality in terms of geometric dimension and surface finish deteriorates with the increase of grain size and the miniaturized thickness of sheet metal, which is related to the limited formability of few grains involved in the shear deformation.

Fracture mechanism changes from ductile dimples to ductile fracture with slip separation while scaling down to micro scale. The irregularities occurred with the decrease of punch-die clearance, but the fracture mechanism has no significant change. High shearing velocity worsens the surface finish and leads to surface breakage. Meanwhile, the number of microvoids decreases and the undesirable forming quality appears with the increase of grain size.

\section{References}

1. U. Engel, R. Eckstein, Microforming - from basic research to its realization, Journal of Materials Processing Technology 125 (2002) 35-44.

2. M. Geiger, M. Kleiner, R. Eckstein, N. Tiesler, U. Engel, Microforming, Cirp Ann-Manuf Techn 50(2) (2001) 445-462.

3. F. Vollertsen, Z. Hu, H.S. Niehoff, C. Theiler, State of the art in micro forming and investigations into micro deep drawing, Journal of Materials Processing Technology 151(1-3) (2004) 70-79.

4. F. Vollertsen, H.S. Niehoff, Z. Hu, State of the art in micro forming, Int J Mach Tool Manu 46(11) (2006) 1172-1179.

5. A. Messner, U. Engel, R. Kals, F. Vollertsen, Size Effect in the Fe-Simulation of Micro-Forming Processes, Journal of Materials Processing Technology 45(1-4) (1994) 371-376.

6. F. Vollertsen, D. Biermann, H.N. Hansen, I.S. Jawahir, K. Kuzman, Size effects in manufacturing of metallic components, Cirp Ann-Manuf Techn 58(2) (2009) 566-587.

7. M.W. Fu, W.L. Chan, A review on the state-of-theart microforming technologies, Int J Adv Manuf Tech 67(9-12) (2013) 2411-2437.
8. M.W. Fu, W.L. Chan, Micro-scaled products development via microforming: deformation behaviors, processes, tooling and its realization, Springer, Berlin Google Scholar, 2014.

9. K. Hirota, Fabrication of micro-billet by sheet extrusion, Journal of Materials Processing Technology 191(1-3) (2007) 283-287.

10. E. Ghassemali, A.E.W. Jarfors, M.J. Tan, S.C.V. Lim, On the microstructure of micro-pins manufactured by a novel progressive microforming process, Int J Mater Form 6(1) (2013) 65-74.

11. E. Ghassemali, M.J. Tan, A.E.W. Jarfors, S.C.V. Lim, Progressive microforming process: towards the mass production of micro-parts using sheet metal, Int J Adv Manuf Tech 66(5-8) (2013) 611-621.

12. W.L. Chan, M.W. Fu, Meso-scaled progressive forming of bulk cylindrical and flanged parts using sheet metal, Materials \& Design 43 (2013) 249-257.

13. M.W. Fu, W.L. Chan, Micro-scaled progressive forming of bulk micropart via directly using sheet metals, Materials \& Design 49 (2013) 774-783.

14. B. Meng, M.W. Fu, C.M. Fu, K.S. Chen, Ductile fracture and deformation behavior in progressive microforming, Materials \& Design 83 (2015) 14-25.

15. B. Meng, M.W. Fu, C.M. Fu, J.L. Wang, Multivariable analysis of micro shearing process customized for progressive forming of micro-parts, Int J Mech Sci 93 (2015) 191-203.

16. B. Meng, M.W. Fu, S.Q. Shi, Deformation characteristic and geometrical size effect in continuous manufacturing of cylindrical and variable-thickness flanged microparts, Journal of Materials Processing Technology 252 (2018) 546558.

17. J. Xu, B. Guo, C.J. Wang, D.B. Shan, Blanking clearance and grain size effects on micro deformation behavior and fracture in micro-blanking of brass foil, Int J Mach Tool Manu 60 (2012) 27-34.

18. E. Ghassemali, A. Jarfors, M. Tan, S. Lim, Deadzone formation and micro-pin properties in progressive microforming process, ICTP 2011, 10th International Conference on Technology of Plasticity, Steel Research International: Special Edition, Aachen, DE, Sep 25-29, 2011, Wiley-VCH Verlagsgesellschaft, 2011, pp. 1014-1019.

19. M. Geiger, F. Vollertsen, R. Kals, Fundamentals on the manufacturing of sheet metal microparts, Cirp Ann-Manuf Techn 45(1) (1996) 277-282. 